(1)

CrossMark

\title{
Risk of COPD in smokers with low transfer factor
}

\author{
To the Editor:
}

We are concerned that the paper by HARveY et al. [1] in a recent issue of the European Respiratory Journal and its accompanying editorial [2] are misleading the readership with regard to the possible association between gas transfer (TLCO), referred to in the paper as diffusion capacity, and the subsequent risk of developing chronic obstructive pulmonary disease (COPD) in smokers. The authors selected two small groups of subjects ( $\mathrm{n}=59$ and 46) from within a larger dataset to compare what happened to their forced expiratory volume in $1 \mathrm{~s}(\mathrm{FEV} 1)$ to forced vital capacity (FVC) ratio over time. Both groups at baseline had FEV $1>80 \%$ of predicted and FEV1/FVC $>0.7$, but one group had TLCO $>80 \%$ of predicted, and the other group had TLCO $<80 \%$ of predicted and also below a lower $95 \%$ confidence limit of TLCO per cent of predicted as derived by the authors from the data of a separate set of 405 healthy nonsmokers (whose data were not disclosed). This latter extra criterion is only evident from reading the online supplement and it does not readily relate to a true population lower limit as it is based on per cent of predicted values (vide infra). When comparing these two groups the authors found more subjects in their "low TLCO group" had developed airflow obstruction on follow-up. The article and editorial suggest that TLCO $<80 \%$ of predicted is a marker of susceptibility for developing airflow limitation and COPD in smokers. However, the authors have not assessed what happened to their subjects whose TLCO is below $80 \%$ of predicted but is also above the authors' $95 \%$ confidence limit. From figure 1 it can be seen that the true population lower $95 \%$ confidence limit in older and smaller subjects can be a long way below $80 \%$ of predicted. So it is misleading to suggest that a threshold of $80 \%$ of predicted for TLCO has any particular merit in predicting future airflow obstruction when the authors have not assessed what happened to the many subjects who will have a value below this level but above the authors' lower 95\% confidence limit that defined their low TLCO group. Furthermore they claim they find a predictor of COPD and yet no evidence is offered with regard to the symptoms required for making this diagnosis.

This deception is compounded by a number of other issues. Using per cent of predicted to differentiate levels of lung function impairment between subjects is flawed because this methodology retains age, sex and size biases [3], which are the very aspects that reference to a predicted value is trying to remove. Furthermore, using FEV1/FVC $<0.7$ to define airflow obstruction does not take age-related changes into account. Some younger subjects may have a value $>0.7$ with this being abnormally low and, for older subjects, values $<0.7$ can be within the accepted range for their age. The duration of follow-up and the number of assessments ranged widely between individuals and this introduces the potential for bias. TLCO

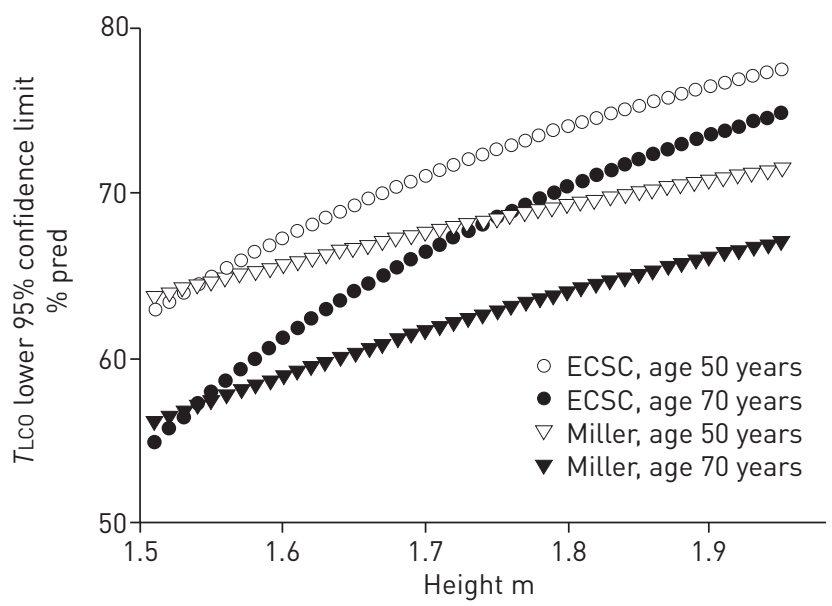

FIGURE 1 The population lower 95\% confidence limit for gas transfer ( $T$ LCO) in men expressed as per cent of predicted plotted against height for two different age groups using the equations from the European Coal and Steel Community (ECSC) [4] and MILLER et al. [5]. The findings for women are similar. 
is known to be related to the age, the sex and the size of the subject $[4,5]$. For size, the subject's height is often used, but for the equation used by the authors alveolar volume (VA) is used in the prediction [6]. In the paper the subjects' $V$ A values are not stated so the reader also does not know how much size differences might affect the authors' results.

For these reasons we believe the paper and editorial are potentially misleading. If authors wish to publish using fixed thresholds to make clinical judgements they must undertake a comprehensive and unbiased analysis that includes a comparison with true population lower limits of normal, a methodology that adheres to conventional statistical principles. The field of COPD research requires publications that offer clarification on these and other issues so clinicians are then best able to improve the management of this condition.

@ERSpublications

The subsequent development of COPD has not yet been proven to relate to a particular threshold value of TLCO http://ow.ly/XAlx1

Martin R. Miller ${ }^{1}$ and Vito Brusasco ${ }^{2}$

${ }^{1}$ Institute of Occupational and Environmental Medicine, University of Birmingham, Birmingham, UK. ${ }^{2}$ Dipartimento di Medicina Interna e Specialità Mediche, Università di Genova, Genoa, Italy.

Correspondence: Martin R. Miller, Institute of Occupational and Environmental Medicine, University of Birmingham, Birmingham, B15 2TT, UK. E-mail: martin@millermr.com

Received: Dec 312015 | Accepted after revision: Jan 142016

Conflict of interest: None declared.

\section{References}

1 Harvey B-G, Strulovici-Barel V, Kaner RJ, et al. Risk of COPD with obstruction in active smokers with normal spirometry and reduced diffusion capacity. Eur Respir J 2015; 46: 1589-1597.

2 Mannino DM, Make BJ. Is it time to move beyond the "O" in early COPD? Eur Respir J 2015; 46: 1535-1537.

3 Miller MR. Does the use of per cent of predicted have any evidence base? Eur Respir J 2015; 45: 322-323.

4 Quanjer PH, Tammeling GJ, Cotes JE, et al. Standardized lung function testing. Lung volumes and forced ventilatory flows. Eur Respir J 1993; 6: Suppl. 16, 5-40.

5 Miller A, Thornton JC, Warshawe R, et al. Single breath diffusing capacity in a representative sample of the population of Michigan, a large industrial state. Predicted values, lower limits of normal, and frequencies of abnormality by smoking history. Am Rev Respir Dis 1983; 127: 270-277.

6 Gaensler EA, Smith AA. Attachment for automated single breath diffusing capacity measurement. Chest 1973; 63: $136-145$.

Eur Respir J 2016; 47: 1885-1886 | DOI: 10.1183/13993003.02218-2015 | Copyright (CERS 2016

\section{To the Editor:}

In a recent issue of the European Respiratory Journal, HARvEY et al. [1] measured spirometry and transfer factor on two occasions in 105 smokers (74\% African-Americans). Throughout the study, there was no evidence of respiratory disease. Whilst all had a forced expiratory volume in $1 \mathrm{~s}$ (FEV1)/forced vital capacity (FVC) ratio $>0.7$, in 46 , the measured transfer factor of the lung for carbon monoxide (TLCO) was $<80 \%$ predicted. In 15 out of 59 subjects with normal values, TLCO fell below $80 \%$ predicted during follow-up; in two, the FEV1/FVC ratio declined slightly below 0.7. Of the 46 subjects with TLCO $<80 \%$ predicted, the FEV1/FVC ratio declined to $<0.7$. The authors conclude that a normal-spirometry, low-TLCO phenotype is a risk factor for developing chronic obstructive pulmonary disease. However, there are several flaws in this study that invalidate the conclusion.

An FEV1/FVC ratio $<0.7$ but above the lower limit of normal (LLN) (fifth centile) is not associated with respiratory disease [2]. Curiously, whereas the $95 \%$ reference range for biochemical entities in healthy subjects, which are homeostatically controlled, is universally accepted as a normal range, reference ranges are still not generally used in respiratory medicine. Thus, many regard a fixed FEV1/FVC ratio of 0.7 as the LLN. However, this index is not homeostatically controlled but varies with age, height and sex; it is above this threshold in subjects $<45$ years of age and below it in elderly subjects. In a male and female of average height, the ratio declines from 0.7 to 0.65 between ages 40 and 65 years [3]. In a healthy population, $5 \%$ of spirometric indices fall below the LLN. Judging from the age range and illustrations, it 